\title{
Treatment Options for Cranial Cruciate Ligament Rupture In Dog - A Literature Review
}

\author{
Cornel Igna* and Larisa Schuszler \\ Banat's University of Agricultural Science and Veterinary Medicine Timisoara, Faculty of Veterinary Medicine, Romania
}

Received: March 06, 2018; Published: March 20, 2018

*Corresponding author: Cornel Igna, Banat's University of Agricultural Science and Veterinary Medicine Timisoara, Faculty of Veterinary Medicine, 119 Calea Aradului, 300645, Timisoara, Romania, Tel: 0726018855; Email: corneligna@usab-tm.ro

\begin{abstract}
Cranial cruciate ligament (CrCL) breaks in dogs can be treated by surgical and non-surgical methods. Choice of the treatment method of cranial cruciate ligament rupture in dog continues to be a real problem for veterinarian clinicians. This topic has been the subject of many studies. Investigation of the speciality literature data concerning the surgical treatment options in the management of cranial cruciate ligament injuries) in dogs, remains, in the conditions of an informational avalanche, a present concern, The purpose of this study was to analyze additional evidence which have appeared in the literature in the period of 2006 - January 2017 and which advocate with concrete evidences in the favour or disfavour of a particular method of dogs' cranial cruciate ligament injuries treatment. Analysis of online searches using PubMed engine in 403 articles suggest that the data analyzed do not allow accurate comparisons between different treatment procedures of cranial cruciate ligament deficiency in dogs and did not show significant differences nor major changes when compared to previous reports (from 1963 to 2005). New long-term clinical studies must be designed and further biomechanical and kinematic analyses are required to determine the optimal technique, and whether these procedures are superior to other stabilization methods.
\end{abstract}

Keywords: Cranial Cruciate ligament deficiency; Dog; Treatment procedures; Trend

\section{Introduction}

Choice of the treatment method of cranial cruciate ligament (CrCL) rupture in dogs continues to be a real problem for veterinarian clinicians. This topic has been, since 1963 [1], the subject of many concerns and studies. CrCL breaks in dogs can be treated by surgical and non-surgical methods. The latest study investigating the speciality literature on surgical treatment options in the management of CrCL ruptures in dogs was published in 2005 [2] after an online bibliographic search through Medline, PubMed, Veterinary Information Network, and Commonwealth Agricultural Bureau Abstracts, with 240 sources being found and analyzed, and it ends with the conclusion „At this time, the application of evidence-based medicine in analyzing the current available evidence suggests that there is not a single surgical procedure that has enough data to recommend that it can consistently return dogs to normal function after CCL injury".

Referring only to the surgical procedures used to treat dogs' CrCL ruptures, a review from 2011 [3] was focused only on extracapsular procedures and shows that there is no data to allow recommendation of a specific technique being necessary „future studies should be directed toward outlining the virtues and inadequacies of the current techniques" and another study investigating the literature (444 paper works) with constant referring only on surgical procedures occurred in 2014 [4] conclude that tibial plateau levelling osteotomy (TPLO) is superior to the extra capsular lateral side suturing procedures, but there are insufficient data to properly assess other surgical methods. There are also several studies comparing the effectiveness of surgical and non-surgical therapeutic methods, the latest being dated in 2013 [5-7]. The purpose of this study was to analyze additional proof which have appeared lately in the speciality literature in the favour / disfavor of a particular method of CrCL breaks treatment in dog.

\section{Materials and Methods}

In January 2017, an online search was conducted, using three search engines: Google scholar (https://scholar.google.ro), PubMed - US National Library of Medicine National Institutes of Health (https://www.ncbi.nlm.nih.gov/pubmed) and Taylor \& Francis Online (http://www.tandfonline.com). There have been used as basic search term "cranial cruciate ligament rupture in dog" preceded into three main additional insights by the terms „treatment”, nonsurgical treatment”, surgery treatment”, last with 
the following secondary insights „lateral extracapsular stabilization treatment", "tibial plateau levelling osteotomy - TPLO", "tibial tuberosity advancement - TTA", "triple tibial osteotomy - TTO" and "Maquet”. Filtering of the results was done using „most recent” and „best match" for PubMed engine, „article” for Google scholar and subject" and publication date" for Taylor \& Francis Online. The results obtained by investigating PubMed were analyzed Table 1: Number of scientific papers identified online. and classified according to the method proposed by Aragon and Budsberg, 2005 [2], after the evaluation method used:

a) Force plate analysis,

b) Subjective and objective evaluation by the clinician and 3 - subjective evaluation by the pet owner, being considered relevant in this order (1 - maximum and 3 - minimum).

\begin{tabular}{|c|c|c|c|}
\hline \multirow[b]{2}{*}{ Descriptors } & \multicolumn{3}{|c|}{ Search Engines } \\
\hline & $\begin{array}{c}\text { Google scholar (https://scholar. } \\
\text { google.ro) }\end{array}$ & $\begin{array}{l}\text { PubMed - US National Library of } \\
\text { Medicine National Institutes of } \\
\text { Health (https://www.ncbi.nlm.nih. } \\
\text { gov/pubmed) }\end{array}$ & $\begin{array}{c}\text { Taylor \& Francis Online (http:// } \\
\text { www.tandfonline.com) }\end{array}$ \\
\hline $\begin{array}{l}\text { cranial cruciate ligament rupture } \\
\text { in dog }\end{array}$ & 10.600 & 403 & 62 \\
\hline $\begin{array}{l}\text { treatment cranial cruciate ligament } \\
\text { rupture in dog }\end{array}$ & 9550 & 267 & 51 \\
\hline $\begin{array}{l}\text { surgery treatment cranial cruciate } \\
\text { ligament rupture in dog }\end{array}$ & 8530 & 251 & 41 \\
\hline $\begin{array}{l}\text { lateral extracapsular stabilization } \\
\text { treatment in cranial cruciate } \\
\text { ligament rupture in dog }\end{array}$ & 735 & 5 & 2 \\
\hline $\begin{array}{l}\text { tplo treatment in cranial cruciate } \\
\text { ligament rupture in dog }\end{array}$ & 983 & 33 & 4 \\
\hline $\begin{array}{l}\text { tta treatment in cranial cruciate } \\
\text { ligament rupture in dog }\end{array}$ & 465 & 21 & 1 \\
\hline $\begin{array}{l}\text { tto treatment in cranial cruciate } \\
\text { ligament rupture in dog }\end{array}$ & 384 & 3 & 1 \\
\hline $\begin{array}{l}\text { tightrope in cranial cruciate } \\
\text { ligament rupture in dog }\end{array}$ & 140 & 4 & 0 \\
\hline $\begin{array}{l}\text { maquet procedure in cranial } \\
\text { cruciate ligament rupture in dog }\end{array}$ & 162 & 3 & 0 \\
\hline $\begin{array}{l}\text { bone anchor in cranial cruciate } \\
\text { ligament rupture in dog }\end{array}$ & 1340 & 3 & 20 \\
\hline $\begin{array}{l}\text { nonsurgical treatment in cranial } \\
\text { cruciate ligament rupture in dog }\end{array}$ & 1120 & 3 & 1 \\
\hline
\end{tabular}

\section{Results and Discussion}

Results of the bibliographic online introspection are shown in Table 1. The analysis of search results with PubMed engine reveals 403 articles (for the period 1963 - January 2017), respectively 391 after manual excluding of those in whose abstract no connection to CrCL was found. In the period 2006 - January 2017, 216 articles were found regarding CrCL in dog, data that reveals a near doubling of number of articles reviewed by Aragon and Budsberg until August 2004 [2]. Instead, between 2006 and January 2017, only 115 articles have appeared regarding therapeutic results evaluation of dogs' CrCL ruptures from which only 23 were relevant articles of level 1, according to the criterion (evaluation by force plate analysis), 86 articles of level 2 (subjective and objective evaluation by the clinician) and 6 articles of level 3 (subjective evaluation by the pet owner).

Of the 23 articles of level 1, six articles promotes kinematics and force plate analysis methods for the diagnosis of dogs' CrCL ruptures [8-13]; articles describe or compare the results obtained with different techniques of surgical treatment [14-24]; Nelson et al. [11]; Mols et al. [25-27] and two articles describe and compare the results obtained with different nonsurgical treatment techniques versus surgical [28]; Wuchereria et al. [7].

If in 2005 there is the opinion that a correct assessment of effectiveness of dogs' CrCL rupture treatment method only the investigations of level 1 can be considered as reliable [2,29], reaffirmed subsequently $[8,14]$ there are some studies appeared quite recently [25] which conclude that ground reaction forces may be inadequate as a sole method for assessing functional outcome after cranial cruciate ligament repair". Articles of level 2, for the most part, make the inventory of postoperative complications of different treatment types [30-43] or show mixed results of level 2 with 3 [44-46]. The estimated costs of surgical treatment for cranial cruciate ligament ruptures in dogs in USA in 2003 were 1.32 billion dollars [47]. Surgical techniques for the repair of cranial cruciate ligament deficiency can be classified into three categories: intraarticular grafts, extracapsular suture stabilization and proximal tibial osteotomy (Hulton, 2013 
Intra-Articular Stabilization Techniques: Includes, Use autografts, allografts, xenografts, and synthetic materials to replace the affected CrCL Paatsama et al. [48-61] makes the inventory of the main reasons of intra-articular procedures low use: - auto grafts have inferior stiffness and strength compared with normal ligament; - allografts have the inconvenience of collection and storage; - synthetic materials caused intra-articular fibrosis, bone abrasion and chronic inflammatory response; which has limited their use in veterinary medicine.

Extra-Articular Stabilization Techniques: Includes Lateral fabellar suture (LFS), percutaneous placement of the lateral fabellar suture (pLFS), Tightrope (TR) [62], transcondylar toggle system [63], modified lateral extra-capsular technique with bone anchor. The treatment using lateral flabella suture (LFS) remains at this moment the most practiced method, applied particularly in small dogs. The major shortcoming of the method (overloading of suture anchor points) [64] has benefited from the contribution of several studies [65-68] which introduced the concept of anchoring in isometric position (relatively isometric) but also the anchor through bone anchors [69-79]. Efforts to identify the ideal material for suture when lateral fabellar suture is applied were materialized by the dethronement of nylon wires as the main option [74-79] and by promoting polyethylene wires which are stronger, stiffer and elongate less than nylon leader $[60,71,80]$ promising options offers the poly blend wires [81] and braided polyester [69].

Securing of the suture reveals the existence of three systems: a square knot (SQ), a slip knot (SL) and a crimp clamp (CR). Existing data show no new information being maintained the recommendation [82] "that 27-kgt nylon leader line be secured with a SL, and 27-kgt nylon fishing line be secured with a SQ" as the "clamping the first throw of a square knot in monofilament nylon leader material who increases failure load by two percent and stiffness by $16 \%$, and decreases elongation by $12 \%$ " [74] although there are studies showing that "crimping suture alters the biomechanical properties of the loop" [80]. Securing the suture through CR remains a superior method of knotting techniques $[83,84]$ and the wave pattern crimp system is more efficient then the single crimp system [85]. Using tensioning sutures systems before applying a crimp clamp does not bring significant advantages over manual tightening [86].

Difficulties in various procedures' execution are reported to be the bone tunnels creation in TR and anchoring around the fabella in LSF and pLSF [87]. Evaluation of extra capsular therapeutic methods efficiency, although it is the subject of several studies [74,86,88]; Anderson et al. [83]; [89,90]; Guenego et al. [70]; [62,63,70]; Havig et al. $[16,17]$ with mostly positive reports, show that many of these studies are subjective (level 2 and 3). Studies based on analysis of data obtained through force plate measurements show that peak vertical force was $93 \%$ and vertical impulse was $96 \%$ of normal values in the limbs of dogs that had extra-articular stabilization at six months following surgery [90], recorded differences being insignificant when compared to normal preoperative values in all studies which appeared before 2006 [88,89] and after [16,17].
Postoperative complications reported after the application of extraarticular stabilization techniques are between 4.2 and 17.4\% [91]; Frey et al. [33] and a 7.2\% of them required reintervention [91].

Proximal Tibial Osteotomy Techniques: Includes, tibial plateau levelling osteotomy-TPLO, combined tibial plateau levelling osteotomy and tibial tuberosity transposition (TPLO-TTT), tibial tuberosity advancement-TTA with the variants TTA-1, TTA- 2 and TTA-rapid, triple tibial osteotomy -TTO and modified Maquet procedure-MMP. All procedures impart primarily change the biomechanics of the stifle and required specialized and custom equipments. The choice of source of this equipment depend on surgeons' preferences or/and their affiliation to certain product companies [92]. Recent assessments of the effectiveness of therapeutic methods of tibial osteotomy reveals unanimously that locomotor function of the limb with CrCL insufficiency can be improved using the techniques of tibial osteotomy [93]; Dymond et al. [31,17]; Christopher et al. [44]; described so far Slocum and Devine [94-100].

More prospective and retrospective studies [101-104]; Bruce et al. [93]; Haaland \& Sjöström [34]; Lafavere et al. [105] ; Stein et al. [45]; Voss et al. [18]; Duerr et al. [106]; Proot \& Cooke [39]; Moles et al. [43]; Dymond et al. [31,33]; Conkling et al. [107] ; Imholt et al. [36]; Taylor et al. [40,41]; Gatineau et al. [108,109]; Steinberg et al. [46]; Etchepareborde [110]; Hishenson et al. [35]; Rotherford et al. [37, 42, 44]; Etchepareborde [111]; Butterworth and Kydd [30] report one or more complications (osteomyelitis, incisional infections, fractures of the tibia or fibula, broken drill bits, hemorrhage, intra-articular implant displacement, intra-osteotomy screw displacement, retained surgical sponges, broken holding pins or screws, septic arthritis, loose implants, draining tracts, ring sequestrum, incisional inflammation, dehiscence and swelling, oedema and seroma formation, bruising, premature staple removal, patellar tendon swelling, and late meniscal injury) after proximal tibial osteotomy procedures.

In TPLO postoperative complication rates, until 2006, ranged between 45.7 and 28\% [102,104,107]; compared to $22.2-8.4 \%$ after 2006 Duerr et al. [106]; Frey et al. [33,36]; Conkling et al. $[107,109]$ and $4.8 \%$ of the cases requiring implant removal [41]. In TTA, the method introduced in practice in 2002 [103], showed postoperative complication rates between $35.5 \%$ and $11 \%$ [105]; Voss et al. [18]; Dymond et al. [31], with 5.2\% reinterventions [42]. In TTO, postoperative complication rate was between $18 \%$ and 23\% [43]. For MMP, two complications were documented (subsequent meniscal injury) from a series of 12 cases and $10.8 \%$ postoperative complications with $3.1 \%$ reintervention in a series of 65 cases [93]. Comparative analysis of the obtained data (2006-2007) which assess the therapeutic efficiency by force plate measurements or kinematic data between extra-articular stabilization methods and tibial osteotomy methods [17,11,25,27] as well as between different methods of tibial osteotomy [26] does not show significant differences between methods and no major changes when compared to previous reports. 
Non-Surgical Treatment Methods: Includes, administration of non-steroidal anti-inflammatory drugs, weight control, restriction of spontaneous locomotion, physiotherapy including hydrotherapy Baker and Bake; Comerford et al. [6,7]. These methods are usually applicable to small dogs with a body weight below $15 \mathrm{kgs}$ [6]. In the treatment of obese dogs with ruptured CrCL, surgical methods had a success rate (was defined as an affected limb net ground reaction force $>85 \%$ of the value for healthy dogs and $a \geq 10 \%$ improvement of the initial values) at 52 weeks after surgery of $75 \%$ compared to $63.6 \%$ in those treated by non-surgical methods [7]. The data presented are similar to those of previous studies, based only on clinical examination and with a success rate of $85.7 \%$ reported for small dogs with body weight below $15 \mathrm{kgs}$ (Vasseur). Latest data concerning non-surgical methods of treatment (Baker and Bake, 2013; Comerford et al., 2013 [6,7] and veterinarians options for these therapeutic modalities [5] did not show a change in trend compared to previous reports [112], the majority of doctors preferring surgical approaches [113-116].

\section{Conclusion}

Currently available data does not allow accurate comparisons between different treatment procedures of cruciate cranial deficiency in dogs. New long-term clinical studies must design and further biomechanical and kinematic analyses are required to determine the optimal technique, and whether these procedures are superior to other stabilization methods.

\section{Acknowledgement}

This research work was carried out with the support of the project Dezvoltarea infrastructurii de cercetare, educaţie şi servicii în domeniile medicinei veterinare şi tehnologiilor inovative pentru RO 05, cod SMIS-CSNR 2669. This paper was presented in poster format in The International Conference of the University of Agronom Sciences and Veterinary Medicine of Bucharest "Agriculture for life, life for agriculture", June 8-10, 2017, Bucharest, Romania.

\section{References}

1. Foster WJ, Imhoff RK, Cordell JT (1963) Closed-joint repair of anterior cruciate ligament rupture in the dog. J Am Vet Med Assoc1 143: 281-283.

2. Aragon LC, Budsberg CS (2005) Applications of Evidence-Based Medicine: Cranial Cruciate Ligament Injury Repair in the Dog. Vet Surg 34(2): 93-98.

3. Tonks CA, Lewis DD, Pozzi A (2011) A review of extra-articular prosthetic stabilization of the cranial cruciate ligament-deficient stifle. Veterinary and Comparative. Orthopaedics and Traumatology (VCOT) 24(3): 167177.

4. Bergh MS, Sullivan C, Ferrell CL, Troy J, Budsberg SC (2014) Systematic review of surgical treatments for cranial cruciate ligament disease in dogs. Journal of the American Animal Hospital Association 50(5): 315321.

5. Baker SJ, Baker GJ (2013) Surgical versus nonsurgical management for overweight dogs with cranial cruciate ligament rupture. J Am Vet Med Assoc15 243(4): 479.

6. Comerford E, Forster K, Gorton K, Maddox T (2013) Management of cranial cruciate ligament rupture in small dogs: a questionnaire study. Vet Comp Orthop Traumatol 26(6): 493-497.
7. Wucherer KL, Conzemius MG, Evans R, Wilke VL (2013) Short-term and long-term outcomes for overweight dogs with cranial cruciate ligament rupture treated surgically or nonsurgically. J Am Vet Med Assoc 242(10): 1364-1372.

8. Fanchon L, Grandjean D (2007) Accuracy of asymmetry indices of ground reaction forces for diagnosis of hind limb lameness in dogs. Am J Vet Res 68(10): 1089-1094.

9. Sanchez-Bustinduy M, de Medeiros MA, Radke H, Langley-Hobbs S, McKinley T, et al. (2010) Comparison of kinematic variables in defining lameness caused by naturally occurring rupture of the cranial cruciate ligament in dogs. Vet Surg 39(4): 523-530.

10. Pillard P, Gibert S, Viguier E (2012) 3D accelerometric assessment of the gait of dogs with cranial cruciate ligament rupture. Comput Methods Biomech Biomed Engin 15(Suppl 1): 129-131.

11. Nelson SA, Krotscheck U, Rawlinson J, Todhunter RJ, Zhang Z, et al. (2013) Long-Term Functional Outcome of Tibial Plateau Leveling Osteotomy Versus Extracapsular Repair in a Heterogeneous Population of Dogs. Veterinary Surgery 42(1): 38-50.

12. Souza AN, Tatarunas AC, Matera JM (2014) Evaluation of vertical forces in the pads of Pitbulls with cranial cruciate ligament rupture. BMC Vet Res 10(1): 51.

13. Krotscheck U, Todhunter RJ, Nelson SA, Sutter NB, Mohammed HO (2014) Precision and accuracy of ground reaction force normalization in a heterogeneous population of dogs. Vet Surg 43(4): 437-445.

14. Thieman KM, Tomlinson JL, Fox DB, Cook C, Cook JL (2006) Effect of meniscal release on rate of subsequent meniscal tears and ownerassessed outcome in dogs with cruciate disease treated with tibial plateau leveling osteotomy. Vet Surg 35(8): 705-710.

15. Robinson DA, Mason DR, Evans R, Conzemius MG (2006) The effect of tibial plateau angle on ground reaction forces 4-17 months after tibial plateau leveling osteotomy in Labrador Retrievers. Veterinary Surgery 35(3): 294-299.

16. Havig ME, Dyce J, Kowaleski MP, Reynolds LR, Budsberg SC (2007) Relationship of tibial plateau slope to limb function in dogs treated with a lateral suture technique for stabilization of cranial cruciate ligament deficient stifles. Vet Surg 36(3): 245-251.

17. Schaijk FV (2008) Force plate gait analysis to assess functional outcome of tibial tuberosity advancement versus lateral capsular imbrication. Faculty of Veterinary Medicine, Utrecht University PhD thesis.

18. Voss K, Damur DM, Guerrero T, Haessig M, Montavon PM (2008) Force plate gait analysis to assess limb function after tibial tuberosity advancement in dogs with cranial cruciate ligament disease. Vet Comp Orthop Traumatol 21(3): 243-249.

19. Gordon-Evans WJ, Dunning D, Johnson AL, Knap KE (2010) Randomised controlled clinical trial for the use of deracoxib during intense rehabilitation exercises after tibial plateau levelling osteotomy. Vet Comp Orthop Traumatol 23(5): 332-335.

20. Pozzi A, Kim SE, Lewis DD (2010) Effect of transection of the caudal menisco-tibial ligament on medial femorotibial contact mechanics. Vet Surg 39(4): 489-495.

21. Morgan JP, Voss K, Damur DM, Guerrero T, Haessig M, et al. (2010) Correlation of radiographic changes after tibial tuberosity advancement in dogs with cranialcruciate-deficient stifles with functional outcome. Vet Surg 39(4): 425-432.

22. Gordon-Evans WJ, Dunning D, Johnson AL, Knap KE (2011) Effect of the use of carprofen in dogs undergoing intense rehabilitation after lateral fabellar suture stabilization. J Am Vet Med Assoc 239(1): 75-80.

23. de Medeiros M, Sánchez Bustinduy M, Radke H, Langley-Hobbs S, Jeffery N (2011) Early kinematic outcome after treatment of cranial cruciate ligament rupture by tibial plateau levelling osteotomy in the dog. Vet Comp Orthop Traumatol 24(3): 178-184. 
24. Böddeker J, Drüen S, Meyer-Lindenberg A, Fehr M, Nolte I, et al. (2012) Computer-assisted gait analysis of the dog: comparison of two surgical techniques for the ruptured cranial cruciate ligament. Vet Comp Orthop Traumatol 25(1): 11-21.

25. Mölsä SH, Hyytiäinen HK, Hielm-Björkman AK, Laitinen-Vapaavuori OM (2014) Long-term functional outcome after surgical repair of cranial cruciate ligament disease in dogs. BMC Vet Res 10: 266.

26. Rey J, Fischer MS, Böttcher P (2014) sagittal joint instability in the cranial cruciate ligament insufficient canine stifle. Caudal slippage of the femur and not cranial tibial subluxation. Tierarztl Prax Ausg K Kleintiere Heimtiere 42(3): 151-156.

27. Berger B, Knebel J, Steigmeier-Raith S, Reese S, Meyer-Lindenberg A (2015) Long-term outcome after surgical treatment of cranial cruciate ligament rupture in small breed dogs. Comparison of tibial plateau leveling osteotomy and extra-articular stifle stabilization. Tierarztl Prax Ausg K Kleintiere Heimtiere 43(6): 373-380.

28. Silva RF, Carmona JU, Rezende CM (2013) Intra-articular injections of autologous platelet concentrates in dogs with surgical reparation of cranial cruciate ligament rupture: a pilot study. Vet Comp Orthop Traumatol 26(4): 285-290.

29. Houlton EFJ (2013) Stifle surgery: cranial cruciate disease and management of patellar luxations. Crieff 2 Day Small Animal CPD Meeting, Vets Now Ltd p. 27-49.

30. Butterworth SJ, Kydd DM (2017) TTA-Rapid in the treatment of the canine cruciate deficient stifle: short-and medium-term outcome. Journal of Small Animal Practice 58(1): 35-41.

31. Dymond NL, Goldsmid SE, Simpson DJ (2010) Tibial tuberosity advancement in 92 canine stifles: initial results, clinical outcome and owner evaluation. Australian veterinary journal 88(10): 381-385.

32. Fitzpatrick N, Solano MA (2010) Predictive variables for complications after TPLO with stifle inspection by arthrotomy in 1000 consecutive dogs. Veterinary surgery 39(4): 460-474.

33. Frey TN, Hoelzler MG, Scavelli TD, Fulcher RP, Bastian RP (2010) Risk factors for surgical site infection-inflammation in dogs undergoing surgery for rupture of the cranial cruciate ligament: 902 cases (20052006). Journal of the American Veterinary Medical Association 236(1): 88-94.

34. Haaland PJ, Sjöström L (2007) Luxation of the long digital extensor tendon as a complication to Tibial Plateau Levelling Osteotomy - A presentation of four cases. Vet Comp Orthop Traumatol 20(3): 224-226.

35. Hirshenson MS, Krotscheck U, Thompson MS, Knapp-Hoch HM, Jay-Silva AR, et al. (2012) Evaluation of complications and short-term outcome after unilateral or single-session bilateral tibial tuberosity advancement for cranial cruciate rupture in dogs. Veterinary and Comparative Orthopaedics and Traumatology (VCOT) 25(5): 402-409.

36. Imholt KM, Möller S, Fehr M, Meyer-Lindenberg A (2011) Lameness and osteoarthritis following Tibial Plateau Leveling Osteotomy (TPLO) and potential prognostic predictors. Tierärztliche Praxis Kleintiere 39(5): 323-335.

37. Rutherford S, Bell JC, Ness MG (2012) Fracture of the patella after TPLO in 6 dogs. Veterinary Surgery 41(7): 869-875.

38. Stauffer KD, Tuttle TA, Elkins AD, Wehrenberg AP, Character BJ (2006) Complications associated with 696 tibial plateau leveling osteotomies (2001-2003). Journal of the American Animal Hospital Association 42(1): 44-50.

39. Proot J, Cooke S (2009) Tibial tuberosity advancement: Technique and postoperative complications. Companion Animal 14(5): 25-30.

40. Taylor J, Langenbach A, Marcellin-Little DJ (2011) Risk factors for fibular fracture after TPLO. Veterinary Surgery 40(6): 687-693.

41. Thompson AM, Bergh MS, Wang C, Wells K (2011) Tibial plateau levelling osteotomy implant removal: A retrospective analysis of 129 cases. Veterinary and Comparative Orthopaedics and Traumatology (VCOT) 24(6): 450-456.

42. Wolf RE, Scavelli TD, Hoelzler MG, Fulcher RP, Bastian RP (2012) Surgical and postoperative complications associated with tibial tuberosity advancement for cranial cruciate ligament rupture in dogs: 458 cases (2007-2009). Journal of the American Veterinary Medical Association 240(12): 1481-1487.

43. Moles AD, Hill TP, Glyde M (2009) Triple tibial osteotomy for treatment of the canine cranial cruciate ligament-deficient stifle joint. Veterinary and Comparative Orthopaedics and Traumatology (VCOT) 22(6): 473478.

44. Christopher SA, Beetem J, Cook JL (2013) Comparison of long-term outcomes associated with three surgical techniques for treatment of cranial cruciate ligament disease in dogs. Veterinary Surgery 42(3): 329-334.

45. Stein S, Schmoekel H (2008) Short-term and eight to 12 months results of a tibial tuberosity advancement as treatment of canine cranial cruciate ligament damage. Journal of Small Animal Practice 49(8): 398-404.

46. Steinberg EJ, Prata RG, Palazzini K, Brown DC (2011) Tibial tuberosity advancement for treatment of CrCL injury: complications and owner satisfaction. Journal of the American Animal Hospital Association 47(4): 250-257.

47. Wilke VL, Robinson DA, Evans RB, Rothschild MF, Conzemius MG (2005) Estimate of the annual economic impact of treatment of cranial cruciate ligament injury in dogs in the United States. Journal of the American Veterinary Medical Association 227(10): 1604-1607.

48. Paatsama S (1952) Ligament injuries in the canine stifle joint. Kauppakirjapaino OY, Helsinki, Finland.

49. Leighton RL, Brightman AH (1976) Experimental and clinical evaluation of a new prosthetic anterior cruciate ligament in the dog. J Am Anim Hosp Assoc 12: 735-740.

50. Arnoczky SP, Tarvin GB, Marshall JL, Saltzman B (1979) the over-the-top procedure: A technique for anterior cruciate ligament substitution in the dog. J Am Anim Hosp Assoc 15: 283-287.

51. Hulse DA, Michaelson F, Johnson C, Abdelbaki YZ (1980) A technique for reconstruction of the anterior cruciate ligament in the dog: Preliminary report. Veterinary Surgery 9(4): 135-140.

52. Meyers JF, Grana WA, Lesker PA (1979) Reconstruction of the anterior cruciate ligament in the dog: comparison of results obtained with three different porous synthetic materials. The American journal of sports medicine 7(2): 85-90.

53. Andnsh JT, Woods LD (1984) Dacron augmentation in antenor cruciate ligament reconstruction in dogs. Clin Orthop 183: 298-302.

54. Curtis RJ, Delee JC, Drez DJ (1985) Reconstruction of the anterior cruciate ligament with freeze dried fascia lata allografts in dogs A preliminary report. The American journal of sports medicine 13(6): 408-414.

55. Yoshiya S, Andrish JT, Manley MT, Kurosaka M (1986) Augmentation of anterior cruciate ligament reconstruction in dogs with prostheses of different stiffnesses. Journal of orthopaedic research 4(4): 475-485.

56. Yoshiya S, Andrish JT, Manley MT, Bauer TW (1987) Graft tension in anterior cruciate ligament reconstruction: an in vivo study in dogs. The American journal of sports medicine 15(5): 464-470.

57. Vasseur PB (1984) Clinical Results Following Nonoperative Management for Rupture of the Cranial Cruciate Ligament in Dogs. Veterinary Surgery 13: $243-246$.

58. Stead AC, Amis AA, Campbell JR (1991) Use of a polyester fibre as a prosthetic cranial cruciate ligament in small animals. J Small Anim Pract 32: 448-453.

59. Aiken SW, Badylak SF, Toombs JP, KD Shelbourne, MC Hiles, et al., (1994) Small intestinal submucosa as an intra-articular ligamentous graft material: a pilot study in dogs. Vet Comp Orthop Traumatol 7: 124-128. 
60. Tonks CA, Pozzi A, Ling HY, Lewis DD (2010) The Effects of Extra-Articular Suture Tension on Contact Mechanics of the Lateral Compartment of Cadaveric Stifles Treated with the TightRope CCL or Lateral Suture Technique. Veterinary Surgery 39(3): 343-349.

61. Vasseur PB (2003) Stifle joint. In: Slatter D (Eds.). Textbook of Small Animal Surgery, (3 ${ }^{\text {rd }}$ Edition) Philadelphia, Saunders, USA, pp. 20902133.

62. Cook JL, Luther JK, Beetem J, Karnes J, Cook CR (2010) Clinical comparison of a novel extracapsular stabilization procedure and tibial plateau leveling osteotomy for treatment of cranial cruciate ligament deficiency in dogs. Veterinary Surgery 39(3): 315-323.

63. Kunkel KA, Basinger RR, Suber JT, Gerard PD (2009) Evaluation of a transcondylar toggle system for stabilization of the cranial cruciate deficient stifle in small dogs and cats. Vet Surg 38(8): 975-982.

64. Fischer C, Cherres M, Grevel V, Oechtering G, Böttcher P (2010) Effects of attachment sites and joint angle at the time of lateral suture fixation on tension in the suture for stabilization of the cranial cruciate ligament deficient stifle in dogs. Veterinary surgery 39(3): 334-342.

65. Roe SC, Kue J, Gemma J (2008) Isometry of potential suture attachment sites for the cranial cruciate ligament deficient canine stifle. Veterinary and Comparative Orthopaedics and Traumatology (VCOT) 21(3): 215220.

66. Hulse D, Hyman W, Beale B, Saunders B, Peycke L, et al. (2010) Determination of isometric points for placement of a lateral suture in treatment of the cranial cruciate ligament deficient stifle. Veterinary and Comparative Orthopaedics and Traumatology (VCOT) 23(3): 163-167.

67. De Sousa RJ, Knudsen CS, Holmes MA, Langley-Hobbs SJ (2014) QuasiIsometric Points for the Technique of Lateral Suture Placement in the Feline Stifle Joint. Veterinary Surgery 43(2): 120-126.

68. Cinti F, Signorelli C, Lopomo N, Baracchi M, Del Magno S, et al. (2015) Two different approaches for novel extracapsular cranial cruciate ligament reconstruction: an in vitro kinematics study. Journal of Small Animal Practice 56(6): 398-406.

69. Guenego L, Zahra A, Madelenat A, Gautier R, Marcellin-Little DJ, et al., (2007) Cranial cruciate ligament rupture in large and giant dogs. A retrospective evaluation of a modified lateral extracapsular stabilization. Vet Comp Orthop Traumatol 20(1): 43-50.

70. Hulse D, Saunders B, Beale B, Kowaleski M (2011) Extra-articular stabilization of the cranial cruciate deficient stifle with anchor systems. Tierärztliche Praxis Kleintiere 39(5): 363-367.

71. Choate CJ, Pozzi A, Lewis DD, Hudson CC, Conrad BP (2012) Mechanical properties of isolated loops of nylon leader material, polyethylene cord, and polyethylene tape and mechanical properties of those materials secured to cadaveric canine femurs via lateral femoral fabellae, toggles placed through bone tunnels, or bone anchors. American journal of veterinary research 73(10): 1519-1529.

72. Raske M, Hulse D (2013) Swive Lock Bone Anchor Stabilization of the Cranial Cruciate Ligament Deficient Stifle in Dogs: Clinical Outcome. Open Journal of Veterinary Medicine 3(07): 297.

73. Citi S (2015) L'àncora di sutura nell'incompetenza del LCA nel cane: modifiche alla tecnica mininvasiva extracapsulare standard. Aivpa Journal 4(3): 22-26.

74. Caporn TM, Roe SC (1996) Biomechanical evaluation of the suitability of monofilament nylon fishing line and leader line for extra-articular stabilization of the cranial cruciate-deficient stifle. Vet Comp Orthop Traumatol 9: 126-133.

75. Lewis DD, Milthorpe BK, Bellenger CR (1997) Mechanical comparison of materials used for extra-capsular stabilisation of the stifle joint in dogs. Australian Veterinary Journal 75(12): 890-896.

76. Sicard GK, Hayashi K, Manley PA (2002) Evaluation of 5 types of fishing material, 2 sterilization methods, and a crimp-clamp system for extra- articular stabilization of the canine stifle joint. Veterinary Surgery 31(1): 78-84.

77. Sicard GK, Meinen J, Phillips T, Manley PA (1999) Comparison of fishing line for repair of the cruciate deficient stifle. VCOT Archive 12(3): 43-46.

78. Ledecky V, Knazovicky D, Badida M, Dulebova L, Hluchy M, et al. (2012) Mechanical testing of orthopaedic suture material and a crimp clamp system for the extracapsular stabilisation of canine cruciate-deficient stifles. Veterinarni Medicina 57(11): 597-602.

79. Igna C (2013) TPLO or TTA, treatment options for cranial cruciate ligament rupture in dog - a literature review. Lucrări Ştiinţifice Medicină Veterinară Timişoara XLVI(4): 87-99.

80. Burgess R, Elder S, McLaughlin RO, Constable P (2010) In vitro biomechanical evaluation and comparison of Fiber Wire, Fiber Tape, Ortho Fiber, and nylon leader line for potential use during extra articular stabilization of canine cruciate deficient stifles. Veterinary Surgery 39(2): 208-215.

81. Rose ND, Goerke D, Evans RB, Conzemius MG (2012) Mechanical testing of orthopedic suture material used for extra-articular stabilization of canine cruciate ligament-deficient stifles. Veterinary Surgery 41(2): 266-272.

82. Nwadike BS, Roe SC (1998) Mechanical comparison of suture material and knot type used for fabello-tibial sutures. VCOT Archive 11(1): 52-57.

83. Anderson CC, Tomlinson JL, Daly WR, Carson WL, Payne JT, et al. (1998) Biomechanical evaluation of a crimp clamp system for loop fixation of monofilament nylon leader material used for stabilization of the canine stifle joint. Veterinary Surgery 27(6): 533-539.

84. Vianna ML, Roe SC (2006) Mechanical Comparison of Two Knots and Two Crimp Systems for Securing Nylon Line Used for Extra-Articular Stabilization of the Canine Stifle. Veterinary Surgery 35(6): 567-572.

85. Maritato KC, Barnhart MD, Kazanovicz AJ, Naber SJ (2012) In vitro mechanical evaluation and comparison of two crimping devices for securing monofilament nylon and multifilament polyethylene for use in extracapsular stabilization of the canine stifle. Veterinary and Comparative Orthopaedics and Traumatology (VCOT) 25(6): 466-471.

86. Moores AP, Beck AL, Jespers KJ, Wilson AM (2006) Mechanical evaluation of two loop tensioning methods for crimp clamp extracapsular stabilization of the cranial cruciate ligament-deficient canine stifle. Veterinary Surgery 35(5): 476-479.

87. Biskup JJ, Griffon DJ (2014) Technical difficulties during the training phase for Tightrope $₫$ and percutaneous lateral fabellar suture techniques for cranial cruciate ligament repair. Veterinary Surgery 43(3): 347-354.

88. Jevens DJ, DeCamp CE, Hauptman J, Braden TD, Richter M, et al. (1996) Use of force-plate analysis of gait to compare two surgical techniques for treatment of cranial cruciate ligament rupture in dogs. American Journal of Veterinary Research 57(3): 389-393.

89. Budsberg SC, Verstraete MC, Soutas-Little RW, Flo GL, Probst CW (1988) Force plate analyses before and after stabilization of canine stifles for cruciate injury. American journal of veterinary research 49(9): 15221524.

90. Conzemius MG, Evans RB, Besancon MF, Gordon WJ, Horstman CL, et al. (2005) Effect of surgical technique on limb function after surgery for rupture of the cranial cruciate ligament in dogs. Journal of the American Veterinary Medical Association 226(2): 232-236.

91. Casale SA, McCarthy RJ (2009) Complications associated with lateral fabellotibial suture surgery for cranial cruciate ligament injury in dogs: 363 cases (1997-2005). Journal of the American Veterinary Medical Association 234(2): 229-235.

92. Igna C, Bumb D, Tascau M, Rusu L, Dascalu R, et al. (2014) In vitro mechanical testing of monofilament nylon fishing line, for the extracapsular stabilisation of canine stifle joint. Bulletin of University of 
Agricultural Sciences and Veterinary Medicine Cluj-Napoca. Veterinary Medicine 71(1): 124-129.

93. Bruce WJ, Rose A, Tuke J, Robins GM (2007) Evaluation of the triple tibial osteotomy. A new technique for the management of the canine cruciatedeficient stifle. Vet Comp Orthop Traumatol 20(3): 159-168.

94. Slocum B, Devine T (1984) Cranial tibial wedge osteotomy: a technique for eliminating cranial tibial thrust in cranial cruciate ligament repair. J Am Vet Med Assoc 184(5): 564-569.

95. Slocum DB (1996) Jig for use in osteotomies. United States patent, USA, pp. 578.

96. Leonard KC, Kowaleski MP, Saunders WB, McCarthy RJ, Boudrieau RJ (2016) Combined tibial plateau levelling osteotomy and tibial tuberosity transposition for treatment of cranial cruciate ligament insufficiency with concomitant medial patellar luxation. Veterinary and Comparative Orthopaedics and Traumatology (VCOT) 29(6): 536-540.

97. Montavon PM, Damur DM (2002) Advancement of the tibial tuberosity for the treatment of cranial cruciate deficient canine stifle, $1^{\text {st }}$ World Orthopeadic Veterinary Congress, Munich, Germany, 152.

98. Maquet P (1976) Advancement of the tibial tuberosity. Clin Orthop Relat Res 115: 225-230.

99. Samoy Y, Verhoeven G, Bosmans T, Van der Vekens E, de Bakker E, et al. (2015) TTA rapid: description of the technique and short term clinical trial results of the first 50 cases. Veterinary Surgery 44(4): 474-484.

100. Damur DM, Tepic S, Montavon PM (2003) Proximal tibial osteotomy for the repair of cranial cruciate-deficient stifle joints in dogs. VCOT Archive 16(4): 211

101. Pacchiana PD, Morris E, Gillings SL, Jessen CR, Lipowitz AJ (2003) Surgical and postoperative complications associated with tibial plateau leveling osteotomy in dogs with cranial cruciate ligament rupture: 397 cases (1998-2001). Journal of the American Veterinary Medical Association 222(2): 184-193.

102. McCarthy JR (2002) Tibial Plateau Leveling Osteotomy, WSAVA Congress.

103. Priddy NH, Tomlinson JL, Dodam JR, Hornbostel JE (2003) Complications with and owner assessment of the outcome of tibial plateau leveling osteotomy for treatment of cranial cruciate ligament rupture in dogs: 193 cases (1997-2001). Journal of the American Veterinary Medical Association 222(12): 1726-1732.

104. Carey K, Aiken SW, DiResta GR, Herr LG, Monette S (2005) Radiographic and clinical changes of the patellar tendon after tibial plateau leveling osteotomy 94 cases (2001-2003). VCOT Archive 18(4): 235-242
105. Lafaver S, Miller NA, Stubbs WP, Taylor RA, Boudrieau RJ (2007) Tibial tuberosity advancement for stabilization of the canine cranial cruciate ligament-deficient stifle joint: surgical technique, early results, and complications in 101 dogs. Veterinary Surgery 36(6): 573-586.

106. Duerr FM, Duncan CG, Savicky RS, Park RD, Egger EL, et al. (2008) Comparison of surgical treatment options for cranial cruciate ligament disease in large-breed dogs with excessive tibial plateau angle. Veterinary Surgery 37(1): 49-62.

107. Conkling AL, Fagin B, Daye RM (2010) Comparison of tibial plateau angle changes after tibial plateau leveling osteotomy fixation with conventional or locking screw technology. Veterinary Surgery 39(4): 475-481.

108. Gatineau M, Dupuis J, Planté J, Moreau M (2011) Retrospective study of 476 tibial plateau levelling osteotomy procedures. Vet Comp Orthop Traumatol 24(5): 333-341.

109. Coletti T, Anderson M, Gorse MJ, Madsen R (2014) Complications and Biostatistics Associated with Tibial Plateau Leveling Osteotomy 1,519 Cases. Veterinary Surgery 55(3): 249-254.

110. Etchepareborde S, Brunel L, Bollen G, Balligand M (2011) Preliminary experience of a modified Maquet technique for repair of cranial cruciate ligament rupture in dogs. Vet Comp Orthop Traumatol 24(3): 223-227.

111. Etchepareborde S (2014) Adaptation de la procedure de maquet pour le traitement chirurgical de la rupture du ligament croise cranial chez le chien. Universite de Liege PhD thesis.

112. Korvick DL, Johnson AL, Schaeffer DJ (1994) Surgeons' preferences in treating cranial cruciate ligament ruptures in dogs. Journal of the American Veterinary Medical Association 205(9): 1318-1324.

113. Slocum B, Devine T (1993) Tibial plateau leveling osteotomy for repair of cranial cruciate ligament rupture in the canine. Vet Clin North Am Small Anim Pract 23(4): 777-795.

114. Vasseur PB, Stevenson S, Gregory CR, Rodrigo JJ, Pauli S, et al. (1991) Anterior cruciate ligament allograft transplantation in dogs. Clinical orthopaedics and related research 269: 295-304.

115. Wustefeld-Janssens BG, Pettitt RA, Cowderoy EC, Walton MB, Comerford EJ, et al. (2016) Peak Vertical Force and Vertical Impulse in Dogs With Cranial Cruciate Ligament Rupture and Meniscal Injury. Vet Surg 45(1): 60-65.

116. (2012) Kyon Pharma I: TTA-2. Zurich, KYON Pharma.

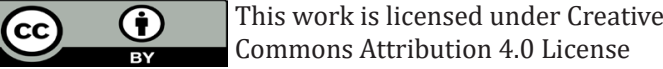

Submission Link: https://biomedres.us/submit-manuscript.php

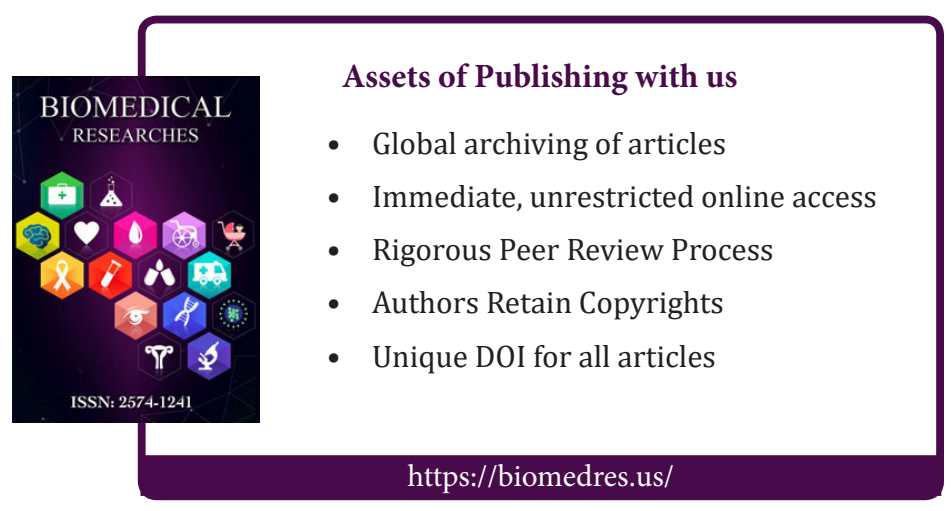

